\title{
25 Research Soure \\ Biological characteristics of rt181T/sW172* HBV are similar among distinct genotypes
}

\section{Wang Huaqiang}

Hainan Modern Women and Children Hospital

Ai Jun

Nanjing Red Cross Blood Center

Zhang Jiajuan

Nanjing Red Cross Blood Center

Zheng Wenkai

General Hospital of Eastern Theater Command

Wang Maorong

General Hospital of Eastern Theater Command

Ping Li ( $\sim$ leep2002@163.com )

Nanjing 81 Hospital of PLA

\section{Research}

Keywords: hepatitis B virus; mutation; drug-resistance; genotypes.

Posted Date: July 30th, 2020

DOI: https://doi.org/10.21203/rs.3.rs-49625/v1

License: (a) This work is licensed under a Creative Commons Attribution 4.0 International License. Read Full License 


\section{Abstract}

Background: The influence of genotypes on disease progression and clinical outcome of HBV infection is noted. The impact of HBV genotypes on rtA181T/sW172* mutation remains unclear.

Patients and Methods: Clinical characteristics of 69 patients with rtA181T/sW172* mutation and 39 patients with rtA181V mutation were analyzed in this study. Fifteen serum specimens with rtA181T/sW172* mutation from different genotypes were collected for cloning and sequence analysis. HBV markers in HepG2 cells encoding different proportions of rtA181T/sW172* mutation and wild type strains were detected in genotype $A, B, C$ and $D$, respectively.

Results: No statistically difference was detected between rtA181T and rtA181V group regarding mean age, sex ratio, liver functions, HBV DNA load and HBeAg positive rate, except for HBsAg level (rtA181T group = $3.07 \pm 0.54 \mathrm{lg} \mathrm{IU} / \mathrm{ml}$ vs rtA181V group $=3.29 \pm 0.43 \mathrm{lg} \mathrm{IU} / \mathrm{ml}, P=0.037$ ). Among 69 patients with $\mathrm{rtA} 181 \mathrm{~T} / \mathrm{sW} 172 *$ mutation, HBV genotypes $\mathrm{B}$ and $\mathrm{C}$ accounted for $17.0 \%$ and $83.0 \%$, respectively. The rate of genotype $\mathrm{B}$ was lower in rtA181T group (10.1\%) than that in rtA181V group (29.7\%), whereas genotype $\mathrm{C}$ was higher in rtA181T group (89.9\%) than that in rtA181V group (70.3\%). HBV rtA181T/sW172* mutant coexisted with wild type strains, accounted for $25 \%$ to $90 \%$ in all HBV strains. The distribution proportion showed no statistical difference between genotype $B$ and $C(59.2 \% \pm 24.3 \%$ vs. $61.2 \% \pm 19.1 \%, P=0.86)$. In transfection experiments, the level of HBV DNA was the highest for genotype B, while HBsAg was expressed in the highest level for genotype A. HBsAg and virus particle were barely detected in the supernatants of rtA181T/sW172* HBV clones in all genotypes. As the proportion of wild type HBV plasmid increased, deficiency of rt181T/sW172* mutation was complemented in all genotypes. No significant difference of the relative expression was found among distinct genotypes $(P>0.05)$.

Conclusions: HBV rtA181T/sW172* mutational pattern may be influenced by genotypes, but biological characteristics of this mutation is similar among distinct genotypes.

\section{Background}

Hepatitis B virus (HBV) infection is still a global public health catastrophe that caused over 257 million people suffering chronic infection [1,2]. The use of Nucleos(t)ide analogs (NAs) has been highly successful in controlling HBV replication and preventing the progress of liver disease. However, currently NAs treatment is not curative because it do not target the nuclear cccDNA reservoir, nor do they stimulate host immune responses to eliminate HBV-infected cells [3]. During the long-term therapy, the emergence of drug-resistant mutations in HBV reverse transcriptase (RT) domain is increased, leading to the treatment failure [4]. Among these mutations, the rtA181T mutation is a special multi-drug resistance [5]. It not only decreases the susceptibility to lamivudine (LAM), adefovir dipivoxil (ADV), telbivudine (LDT) and tenofovir (TDF) [6], but also encodes $S$ gene mutation. It has been reported the rtA181T surface stop mutation mainly leads to a stop codon in the S domain, called HBV rtA181T/sW172*, which can affect the biological characteristics and pathogenesis of HBV [7].

$\mathrm{HBV}$ is classified into at least nine genotypes, designated $\mathrm{A}$ to $\mathrm{I}$, based on nucleotide sequence divergence among strains of more than $8 \%$ [8]. Compared to patients with genotype $C$, patients with genotype $B$ have 
earlier HBeAg seroconversion [9], lower risk of reactivation and progression to cirrhosis [10]. Patients with genotype $A$ have more favourable response to interferon-a compared to patients with genotype $D$ [11]. These differences suggest distinct genotypes may influence the severity of liver disease and treatment effectiveness [12]. However, it remains unclear whether there is an association between HBV genotypes and drug-resistant mutations.

In the present study, we aimed to evaluate the relationship of genotypes and rtA181T/sW172* mutation. We analyzed the clinical characteristics of $\mathrm{CHB}$ patients with rtA181T/sW172* mutation, sequenced the rtA181T/sW172* mutant strains by molecular cloning, and detected the virus particle and HBsAg in HepG2 cells encoding rtA181T/sW172* mutation HBV in different genotypes.

\section{Patients And Methods}

\section{Patients}

A total number of 106 patients with chronic HBV infection who visited our hospital from January 2010 to December 2015 were enrolled in the study. They were treated with NAs for more than one year, and scheduled follow-up every 3-6 month. They exhibited viral breakthrough during antiviral treatment and were identified rtA181T/sW172* or rtA181V mutations. The diagnostic criteria were according to the Chinese guidelines for prevention and treatment of CHB (2015 version) [13]. This study was approved by the institutional review board of China Nanjing bayi hospital and all aspects of the study comply with the Declaration of Helsinki. The Ethics Committee specifically approved that no informed consent was required because this was a retrospective study and the data were analyzed anonymously.

\section{Laboratory tests}

Biochemical Indicators were measured by Olympus AU5400 Chemistry System (Beckman Coulter, Switzerland). HBV markers, including hepatitis B surface antigen (HBsAg), hepatitis B e antigen (HBeAg) and anti-HBe, were tested by Chemiluminescent Assay (Architect i2000SR, Abbott Diagnostics, Abbott Park, IL, USA). HBV DNA was quantified by real-time PCR using a commercial detection kit (Kehua Bio-Engineering, China) with the aid of Light Cycler Detection System (ABI 7300 Realtime PCR system, USA). The lower limit of detection for this assay is $50 \mathrm{IU} / \mathrm{mL}$. Serum HBV DNA was extracted using the QIAamp blood mini kit (Qiagen, Germany). The fragments (nt130-nt1129), encompassing the RT domain, were amplified by nested PCR and the HBV strains were detected by direct Sanger sequencing as previously described [14]. Substitutions at positions rt80, rt173, rt180, rt181, rt184, rt202, rt204, rt236, and rt250 were taken as resistance mutations for analysis. HBV genotypes classification assignment were based on phylogenetic analysis of the 1225-bp-long S/Pol gene sequence.

\section{Clone sequencing analysis}

Serum samples from 15 patients with rtA181T/sW172* mutation were randomly selected for clone sequencing analysis. Of them, 5 samples were genotype $B$ and 10 samples were genotype $C \triangle T$ The $P C R$ product was purified and recovered according to the instructions in the PCR Purification Kit (Axygen, Hangzhou, China), connected to T-A vector at $4^{\circ} \mathrm{C}$ overnight, then transformed into E.coli DH5a competent cells. More than 18 positive 
clones were selected for sequencing from each plate. The sequences were aligned using the Clustal W program in Megalign version 3.17 software.

\section{Construction of 1.24-fold genome HBV vectors}

Ae-JPN, Ba-JPN58, C-JPNAT and D-US68 HBV plasmid kindly provided by Sugiyama[15] were used as wild type templates to construct rtA181T/sW172* mutations strain, respectively. Site-directed mutagenesis (Stratagene, La Jolla, CA) were carried out to introduce these mutations. The sequence of the mutagenesis primers for different genotypes are shown in Table 1.

Table 1 Sequences and location of primers for construct HBV rtA181T/V mutation

\begin{tabular}{cccc}
\hline Primer set Primer name & \multicolumn{2}{c}{ Sequence(5'-3') } & Position(nt) \\
\hline Sense & AT-F & 5'-GTCCGTTTCTCTTGACTCAGTTTACTAGTGCC-3' & 656-687 \\
Antisense & AT-R & 5'-GGCACTAGTAAACTGAGTCAAGAGAAACGGAC-3' & 687-656 \\
Sense & CT-F & 5'-GTCCGTTTCTCCTGACTCAGTTTACTAGTGCC-3' & 656-687 \\
Antisense & CT-R & 5'-GGCACTAGTAAACTGAGTCAGGAGAAACGGAC-3' & 687-656 \\
Sense & DT-F & 5'-GCCCGTTTCTCCTGACTCAGTTTACTAGTGCC-3' & 656-687 \\
Antisense & DT-R & 5'-GGCACTAGTAAACTGAGTCAGGAGAAACGGGC-3' & 687-656 \\
\hline
\end{tabular}

The primers were designed completely complementary, the bases marked were sitedirected mutagenesis. The primers for genotype B and genotype A are the same.

\section{Cell transfection, Relative replication and HBsAg expression yield assays}

HepG2 human hepatoma cells were cultured in Dulbecco's modified Eagle medium (DMEM, Gibco) supplemented with $10 \%$ fetal bovine serum (FBS). After $24 \mathrm{~h}$ of culture, cells were transiently transfected with 5 $\mu \mathrm{g}$ plasmids using FuGENE HD Transfection (Roche, Switzerland). Transfection efficiency was measured by cotransfection with $0.1 \mu \mathrm{g}$ pSEAp and determination of alkaline phosphatase activity in cell supernatants using SEAP Reporter Assay Kit (Roche, Switzerland).

After $72 \mathrm{~h}$ post-transfection, HBsAg in cell culture supernatants were detected by ELISA, HBV virions from supernatants were quantified by real-time PCR after the following process. $20 \mu$ l of 10xReaction Buffer (100mM Tris[pH7.5], 25mM MgCl2, $1 \mathrm{mM} \mathrm{CaCl} 2), 2 \mu \mathrm{l}$ of $20 \mathrm{mg} / \mathrm{ml}$ DNAse I, and $1 \mu \mathrm{l}$ of $10 \mathrm{mg} / \mathrm{ml}$ RNAse A (Sigma, Germany) were added to the $180 \mu \mathrm{l}$ solution and incubation at $37^{\circ} \mathrm{C}$ for $2 \mathrm{~h}$, followed by inactivation reaction at $70^{\circ} \mathrm{C}$ for 10 min with EDTA at a final concentration of $10 \mathrm{mM}$ [16]. The HBV replication and $\mathrm{HBsAg}$ expression yield were standardized relative to wild type genotype A, defined as 1.0. All experiments were performed 3 times.

\section{Statistical analysis}

Quantitative data were expressed as means \pm standard deviations and analyzed by independent samples $t$ test or $U$ test. Count data constitute were used $\chi^{2}$ test. Statistical analysis was carried out with SPSS 13.0 software. Significance was set at $P<0.05$. 


\section{Results}

\section{Study population}

Total 106 cases enrolled for the study, 69 (65.1\%) patients appeared rtA181T/sW172* mutation (rtA181T group), the remaining 37 (34.9\%) patients appeared rtA181V mutation (rtA181V group). Their mean age was 42.3 years (23-64 years) with a male: female ratio of 8.64: 1 . Most of them $(104,98.1 \%)$ had a history of ADV medication. After emergence of rtA181T/V mutant, mean serum viral load increased over $4 \log _{10} \mathrm{IU} / \mathrm{mL}$ which was still significant lower than that at baseline $(P<0.05)$. The demographic, biochemical and serological data of the patients are presented in Table2. There was no significant difference among the two groups regarding mean age, sex ratio, liver functions, HBV DNA level and HBeAg positive rate, except for HBsAg level (rtA181T group $=3.07 \pm 0.54 \mathrm{lg} \mathrm{IU} / \mathrm{ml}$ vs rtA181V group $=3.29 \pm 0.43 \mathrm{lg} \mathrm{IU} / \mathrm{ml}, P=0.037)$.

Table 2 Characteristics of HBV rtA181T/V mutant patients

\begin{tabular}{|c|c|c|c|}
\hline Characteristics & rtA181T group $\llbracket n=69 \square$ & rtA181V group $\llbracket n=37 \square$ & $P$ value \\
\hline \multicolumn{4}{|l|}{ Age (years) } \\
\hline Mean \pm SD & $41.3 \pm 9.8$ & $44.3 \pm 9.3$ & 0.135 \\
\hline \multicolumn{4}{|l|}{ Sex(No. ) } \\
\hline Male/ Female & $60 / 9$ & $35 / 2$ & 0.219 \\
\hline \multicolumn{4}{|c|}{ Total bilirubin level $(\mu \mathrm{mol} / \mathrm{L})$} \\
\hline Mean \pm SD & $39.8 \pm 84.1$ & $21.7 \pm 24.4$ & 0.100 \\
\hline \multicolumn{4}{|l|}{$\operatorname{ALT}(\mathrm{U} / \mathrm{L})$} \\
\hline Mean $\pm S D$ & $130.6 \pm 208.8$ & $128.6 \pm 224.7$ & 0.964 \\
\hline \multicolumn{4}{|l|}{ AST (U/L) } \\
\hline Mean \pm SD & $67.5 \pm 80.1$ & $70.2 \pm 104.8$ & 0.883 \\
\hline \multicolumn{4}{|c|}{ HBV DNA $\left(\log _{10} \mathrm{IU} / \mathrm{mL}\right)$} \\
\hline Mean \pm SD & $4.53 \pm 1.47$ & $4.44 \pm 1.16$ & 0.756 \\
\hline \multicolumn{4}{|l|}{ HBsAg $\left(\log _{10} \mathrm{IU} / \mathrm{ml}\right)$} \\
\hline Mean \pm SD & $3.07 \pm 0.54$ & $3.29 \pm 0.43$ & 0.037 \\
\hline \multicolumn{4}{|l|}{ HBeAg (No.) } \\
\hline Positive/ Negative & $60 / 9$ & $29 / 8$ & 0.251 \\
\hline
\end{tabular}

Regarding genotype distribution, genotype $C(88,83.0 \%)$ was predominant in these patients, followed by genotype $B(18,17.0 \%)$, other genotypes were not detected. There was a significant difference between genotypes $\mathrm{B}$ and $\mathrm{C}$ with respect to the mutational patterns of rtA181 $(P=0.010)$. rtA181T variant were seen in 7 patients with genotype $B$ and 62 with genotype $C$, while rtA $181 \mathrm{~V}$ variant were seen in 11 with genotype $B$ and 26 with genotype $C$ (Fig. 1).

\section{Cloning and sequence analysis of rtA181T/sW172* mutant strain}


Diversity of HBV mutant strain was studied by means of molecular cloning and sequence analysis. From Fig.2, we can see rtA181T/sW172* HBV strain coexisted with WT strain in vivo after emergence of drug-resistance. The rtA181T/sW172* HBV distribution account for $25 \%$ to $90 \%$ in all strains. Distribution proportion of rtA181T/sW172* mutant strain showed no significant difference between genotype B (59.2\% $\pm 24.3 \%)$ and genotype $C(61.2 \% \pm 19.1 \%, P=0.86)$. In these clones, we also found few mutations such as rtA181D and rtA181V which can not be detected by PCR direct sequencing in rtAl81T mutant group.

\section{Presence of wild type strain rescued the defects of rtA181T/sW172* mutant HBV in different genotypes}

Drug-resistant strains are usually detected as a mixed population with wild type HBV. It remains unknown whether wild type HBV can rescue the defects of rtA181T/sW172* mutant in all genotypes. Therefore, a cotransfection experiment was carried out. After 3 days in culture, supernatants from different cells were compared for HBV DNA and HBsAg (Fig.3 and Fig.4). The mean value for genotype A wild type was set at 1.0 and used as the reference. The level of HBV DNA was expressed in the highest level for genotype $B$, while HBsAg was the highest for genotype A.

Although the expression of HBsAg and HBV DNA have differences among genotypes, HBsAg and virus particle were barely detected in the supernatants of rtA181T/sW172* HBV clones in genotype A, B, C and D. When the wild type and mutation HBV ratio is 1:9, 9.7\% 27.3\% HBV DNA and 3.5\% 5.3\% HBsAg can be detected in distinct genotypes. No significant difference of the relative expression was found among these genotypes ( $P=0.089$ for HBV DNA, $P=0.885$ for HBsAg, respectively). As the proportion of transfected wild type HBV plasmid increased, replication and secretion were improved in all genotypes. When the ratio is $1: 1$, the yielding was reach about $50 \%$ compared to wild type. There was no significant difference among distinct genotypes ( $P=0.807$ for HBV DNA, $P=0.779$ for HBsAg).

\section{Discussion}

The influence of genotypes on disease progression and clinical outcome of HBV infection has been observed. To date, there is little data about the relationship between genotypes and drug-resistance mutations. The rtA181T/sW172* mutation is a multi-drug resistance which could affect both the L-nucleoside and acyclic phosphonate nucleotide groups [17]. This makes us to focus on the special mutation to carry out the study.

Previous study has reported the rtA181T/sW172* mutation reduces the typical extent of virological breakthrough [18]. In our study, HBV DNA at virological breakthrough were significant lower than that at baseline, which confirmed the deficiency of rt181T/sW172* mutation. This phenomenon has also been described by other drug-resistance mutation [19]. Even if the serum viral load does not rebound very high, we still need to pay attention to these patients because the alanine aminotransferase was obviously abnormal. If these patients fail to change the drug in time, the disease may deteriorate. The HBV rtA181T/sW172* mutation also impaired the secretion of serum HBsAg. A Korean study of 10 patients showed rtA181T/sW172* has no effect on serum HBsAg titers and HBV DNA [20]. In our study, serum viral load showed no significant difference between the rtA181T group and rtA181V group, but HBsAg titer was significant lower in the rtA181T group than that in rtA $181 \mathrm{~V}$ group. This difference may be due to the small number of cases in their study, and this 
found can be explained as: rtA181V mutation only impaired viral replication, while rtA181T/sW172* mutation has a negative effect not only to viral replication but also to HBsAg secretion.

The genotype-associated difference in CHB patients with NAs treatment remains incompletely understood. One study showed the emergence of resistance-associated mutations during lamivudine treatment followed different mutational patterns in HBV genotype B and C [19]. Another study in patients coinfected with HIV and HBV identified delayed viral suppression following TDF therapy in those with HBV genotype A [21]. In China, genotype $B$ and $C$ are the two most commonly found genotypes. Our results suggested that rtA181T mutation was more prevalent in genotype $\mathrm{C}$, while the rtA181V mutation was more prevalent in genotype $\mathrm{B}$. These indicated that different prevalence of the mutational patterns in distinct HBV genotypes, the underlying mechanism may be related to the immunological control in the host to different HBV genotypes [22]. Nevertheless, this hypothesis of different immune regulation has not yet been confirmed, it needs to be further investigated.

Direct PCR sequencing is considered to be the gold standard for detecting genotypic resistance mutations, but it is not the most sensitive. Strains that fall below $20 \%$ of the total viral quasispecies will not be detected. Even those lower than $50 \%$ are often missed in the analysis[23]. By clonal sequence analysis, we confirmed rtA181T/sW172* HBV usually mixed with wild type strain. Unlike mutational patterns, distribution proportion

of mutant strain showed no significant difference between distinct genotypes. Therefore, the clinical indicators in patients with distinct genotypes did not show differences (data not shown).

In the present in vitro study, we demonstrated the difference in the expression of HBV markers among distinct genotypes. However, regardless of the genotypes, HBsAg secretion and viral particles in cells transfected with rtA181T/sW172* HBV were continuously and significantly reduced. As the proportion of wild type HBV strains increased, dose-dependent improvement in HBsAg and viral particle was observed in supernatants of cotransfected cells. There was no significant difference among distinct genotypes in cell experiment. This indicated that the existence of a low percentage of wild type HBV can complement the secretion deficiency of RT/stop codon mutation HBV and allow HBV virion assembly and release of the deficiency [24], which was not influenced by genotypes. This also suggested the biological characteristics of different genotypes HBV are similar after drug-resistance.

In conclusion, the results of this study showed the HBV rtA181T/sW172* mutation decrease the serum HBsAg and HBV DNA, the rtA181 mutational patterns showed difference between genotype B and $\mathrm{C}$. The rtA181T/sW172* HBV distribution account for $25 \%$ to $90 \%$ in all strains, and the wild type strain can rescue the deficiency of rtA181T/sW172* mutant HBV. The biological characteristics of rtA181T/sW172* showed no significant difference among distinct genotypes. However, this research was conducted with an insufficient number of subjects, and only in rtA181 mutation. There might be a limitation of selection bias. It requires further investigation in larger studies to confirm the validity of associations.

\section{Conclusions}

Our results provides evidence for HBV mutational pattern may be influenced by genotypes, but biological characteristics of different genotypes HBV are similar after drug-resistance. This may provide basis on 
treatment strategies for drug-resistant in different genotypes.

\section{Abbreviations}

HBV: Hepatitis B virus; PCR: Polymerase Chain Reaction; ETV: entecavir; LAM: lamivudine; ADV: adefovir dipivoxil; LDT: telbivudine; TDF: tenofovir; CHB: chronic hepatitis B; ALT: alanine aminotransferase; AST: aspartate aminotransferase; HBsAg: hepatitis B surface antigen; HBeAg: hepatitis B e antigen; NAs: Nucleos(t)ide analogs

\section{Declarations}

\section{Acknowledgements}

We thank the anonymous referees and the editor for their comments and suggestions that helped improve the manuscript.

\section{Funding}

This study was supported by grants from Beijing Medical and Health Foundation (20170920).

\section{Availability of data and materials}

The datasets during and/or analyzed during the current study available from the corresponding author on reasonable request.

\section{Authors' contributions}

Study's conception: WHQ, WMR and LP ; Study's design: WMR and LP; Study's performance: WHQ, AJ, ZJJ, ZWK; Writing and revision: WHQ, LP. All authors read and approved the final manuscript.

\section{Competing interests}

The authors declare that they have no competing interests.

\section{Consent for publication}

Not applicable. No personal data were collected in the context of this study.

\section{Ethics approval and consent to participate}

This study was performed with the approval of the institutional review board of China Nanjing bayi hospital and all aspects of the study comply with the Declaration of Helsinki. The Ethics Committee specifically approved that no informed consent was required because this was a retrospective study and the data were analyzed anonymously.

\section{References}


1. Polaris Observatory Collaborators. Global prevalence, treatment, and prevention of hepatitis $B$ virus infection in 2016: a modelling study. Lancet Gastroenterol Hepatol. 2018;3:383-403.

2. World Health Organization. Global Hepatitis Report.(2018) . https://www.who.int/hepatitis/publications/global-hepatitis-report2017/en/. Accessed 13 Dec 2019.

3. Revill PA, Chisari FV, Block JM, Dandri M, Gehring AJ, Guo H, Hu J, Kramvis A, Lampertico P, Janssen HLA, Levrero M, Li W, Liang TJ, Lim SG, Lu F, Penicaud MC, Tavis JE, Thimme R; Members of the ICE-HBV Working Groups; ICE-HBV Stakeholders Group Chairs; ICE-HBV Senior Advisors, Zoulim F. A global scientific strategy to cure hepatitis B. Lancet Gastroenterol Hepatol. 2019;4:545-58.

4. Zhang HY, Liu LG, Ye CY, Chen CH, Hang SX, Zhu Z, Shen HY, Huang ZY, Chen WY, Xue Y. Evolution of drugresistant mutations in HBV genomes in patients with treatment failure during the past seven years (20102016). Virus Genes. 2018;54:41-7.

5. Ahn SH, Park YK, Park ES, Kim JH, Kim DH, Lim KH, Jang MS, Choe WH, Ko SH, Sung IK, Kwon SY, Kim KH. The Impact of the Hepatitis B Virus Polymerase rtA181T Mutation on Replication and Drug Resistance Is Potentially Affected by Overlapping Changes in Surface Gene. J Virol. 2014;88:6805-18.

6. Zhao L, Li X, Cheng Y, Chen R, Shao J, Zhou Y, Li Q, Liao H, Zhao Y, Liu L, Su H, Liu Y, Liu Y, Xu D. Hepatitis $B$ virus rtA181T/sW172non-stop mutation may increase resistance fold to adefovir- and entecavirresistant mutants compared to rtA181T/sW172* mutation. Antiviral Res. 2018;154:26-34

7. Warner N, Locarnini S. The antiviral drug selected hepatitis B virus rtA181T/sW172* mutant has a dominant negative secretion defect and alters the typical profile of viral rebound. Hepatology. 2008;48:8898.

8. Kramvis A. Genotypes and genetic variability of hepatitis B virus. Intervirology. 2014;57,141-50.

9. Chu CJ, Hussain M, Lok AS. Hepatitis B virus genotype $B$ is associated with earlier HBeAg seroconversion compared with hepatitis B virus genotype C. Gastroenterology 2002;122:1756-62.

10. Yu MW, Yeh SH, Chen PJ, Liaw YF, Lin CL, Liu CJ, Shih WL, Kao JH, Chen DS, Chen CJ. Hepatitis B virus genotype and DNA level and hepatocellular carcinoma: a prospective study in men. J Natl Cancer Inst. 2005;97:265-72.

11. Jardi R, Rodriguez-Frias F, Schaper M, Giggi E, Tabernero D, Homs M, Esteban R, Buti M. Analysis of hepatitis B genotype changes in chronic hepatitis B infection: Influence of antiviral therapy. J Hepatol. 2008;49:695-701.

12. Revill PA, Tu T, Netter HJ, Yuen LKW, Locarnini SA, Littlejohn M. The evolution and clinical impact of hepatitis B virus genome diversity. Nat Rev Gastroenterol Hepatol.2020.[Online ahead of print]

13. Chinese Society of Hepatology, Chinese Medical Association, Chinese Society of Infectious Diseases, Chinese Medical Association, Hou JL, lai W. The guideline of prevention and treatment for chronic hepatitis B: a 2015 update. Zhonghua Gan Zang Bing Za Zhi. 2015;23:888-905. [Article in Chinese.]

14. Li P, Geng JB, Li W, Xu XB, Zhang X, Zheng WK, Yu YC, Yang ZG, Wang MR. Antiviral Efficacy of Entecavir for Hepatitis B Virus rtA181V/T Mutants. Virol J. 2017;14:68.

15. Sugiyama M, Tanaka Y, Kato T, Orito E, Ito K, Acharya SK, Gish RG, Kramvis A, Shimada T, Izumi N, Kaito M, Miyakawa Y, Mizokami M. Influence of hepatitis B virus genotypes on the intra- and extracellular expression of viral DNA and antigens. 2006;44:915-24. 
16. Li WP, Warner N, Sozzi V, Yuen L, Colledge D, Li T, Zhuang H, Locarnini S, Revill PA. Hepatitis B virus genotype $\mathrm{C}$ encoding resistance mutations that emerge during adefovir dipivoxil therapy: in vitro replication phenotype. Hepatol Int. 2013;7:443-50.

17. Zoulim F and Locarnini S. Optimal management of chronic hepatitis B patients with treatment failure and antiviral drug resistance. Liver Int. 2013;33Suppl1:116-24.

18. Dai J, Chen EQ, Bai L, Gong DY, Zhou QL, Cheng X, Huang FJ, Tang H. Biological characteristics of the rtA181T/sW172* mutant strain of Hepatitis B virus in animal model. Virol J. 2012;9:280.

19. Pan XP, Li LJ, Du WB, Li MW, Cao HC, Sheng JF. Differences of YMDD mutational patterns, precore/core promoter mutations, serum HBV DNA levels in lamivudine-resistant hepatitis B genotypes B and C. J Viral Hepat. 2007;14:767-74.

20. Kim JH, Jung YK, Joo MK, Kim JH, Yim HJ, Park JJ, Kim JS, Bak YT, Yeon JE, Byun KS. Hepatitis B viral surface mutations in patients with adefovir resistant chronic hepatitis B with A181T/V polymerase mutations. J Korean Med Sci. 2010;25:257-64.

21. Bihl F, Martinetti G, Wandeler G, Weber R, Ledergeber B, Calmy A, Battegay M, Cavassini M, Vernazza P, Caminada AP, Rickenbach M, Bernasconi E; Swiss HIV Cohort Study. HBV genotypes and response to tenofovir disoproxil fumarate in HIV/HBV- coinfected persons. BMC Gastroenterol. 2015;15:79.

22. Loggi E, Gamal N, Bihl F, Bernardi M, Andreone P. Adaptive response in hepatitis B virus infection. J Viral Hepat. 2014;21:305-13.

23. Colledge D, Soppe S, Yuen L, Selleck L, Walsh R, Locarnini S, Warner N. Stop codons in the hepatitis B surface proteins are enriched during antiviral therapy and are associated with host cell apoptosis. Virology. 2017;501:70-8.

24. Wu CC, Li BL, Zhang XY, Zhao KT, Chen YS, Yuan YF, Liu Y, Chen RJ, Xu DP, Chen XW, Lu MJ. Complementation of Wild-Type and Drug-Resistant Hepatitis B Virus Genomes to Maintain Viral Replication and Rescue Virion Production under Nucleos(t)ide Analogs. Virol Sin. 2019;34:377-85.

\section{Figures}




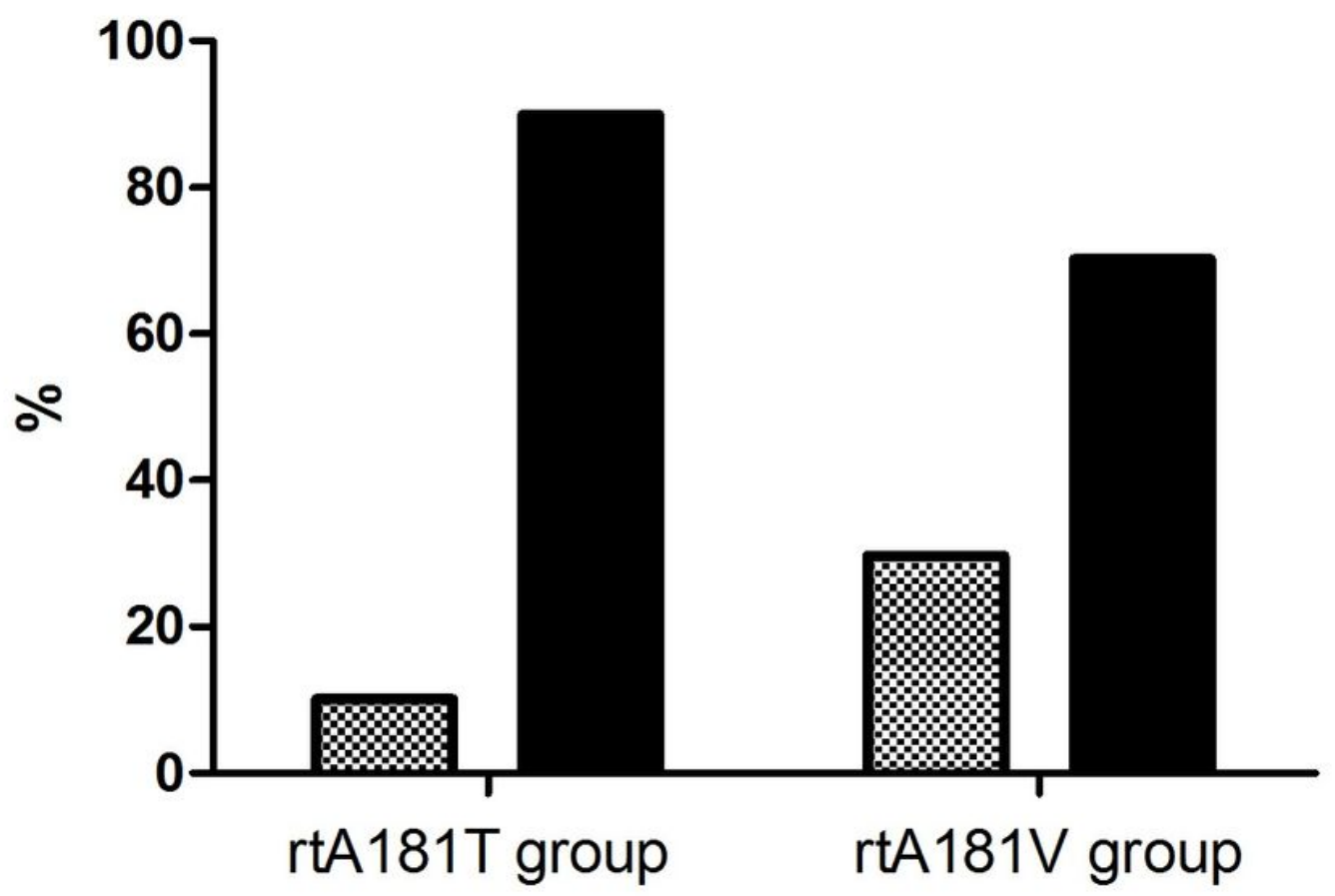

$\otimes$ Genotype B

Genotype C

Figure 1

Relationship between HBV genotypes and mutational patterns of rtA181. The rate of genotype B was lower in rtA181T group (10.1\%) than that in rtA181V group (29.7\%), whereas genotype C was higher in rtA181T group (89.9\%) than that in rtA181V group (70.3\%).

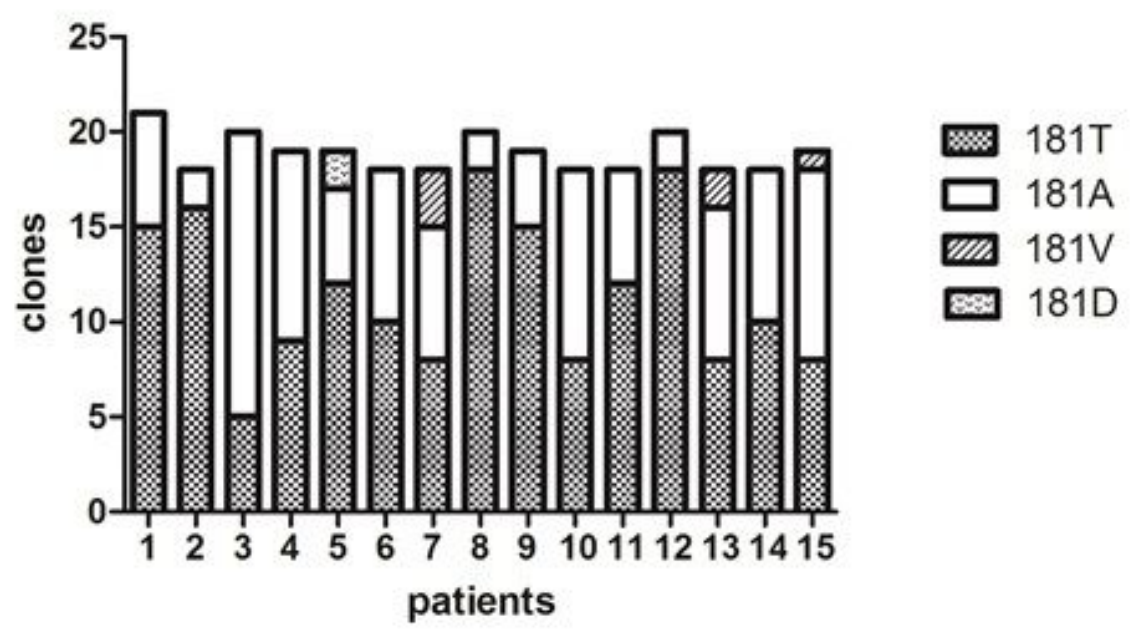

Figure 2

HBV rtA181T/sW172* mutant coexisted with wild type virus. Cloning and sequence analysis of the viral polymerase gene confirmed rtA181T/sW172* mutant HBV as a mixed population with wild type strain. 1-5 were genotype $B$, and 6-10 were genotype $C$. 

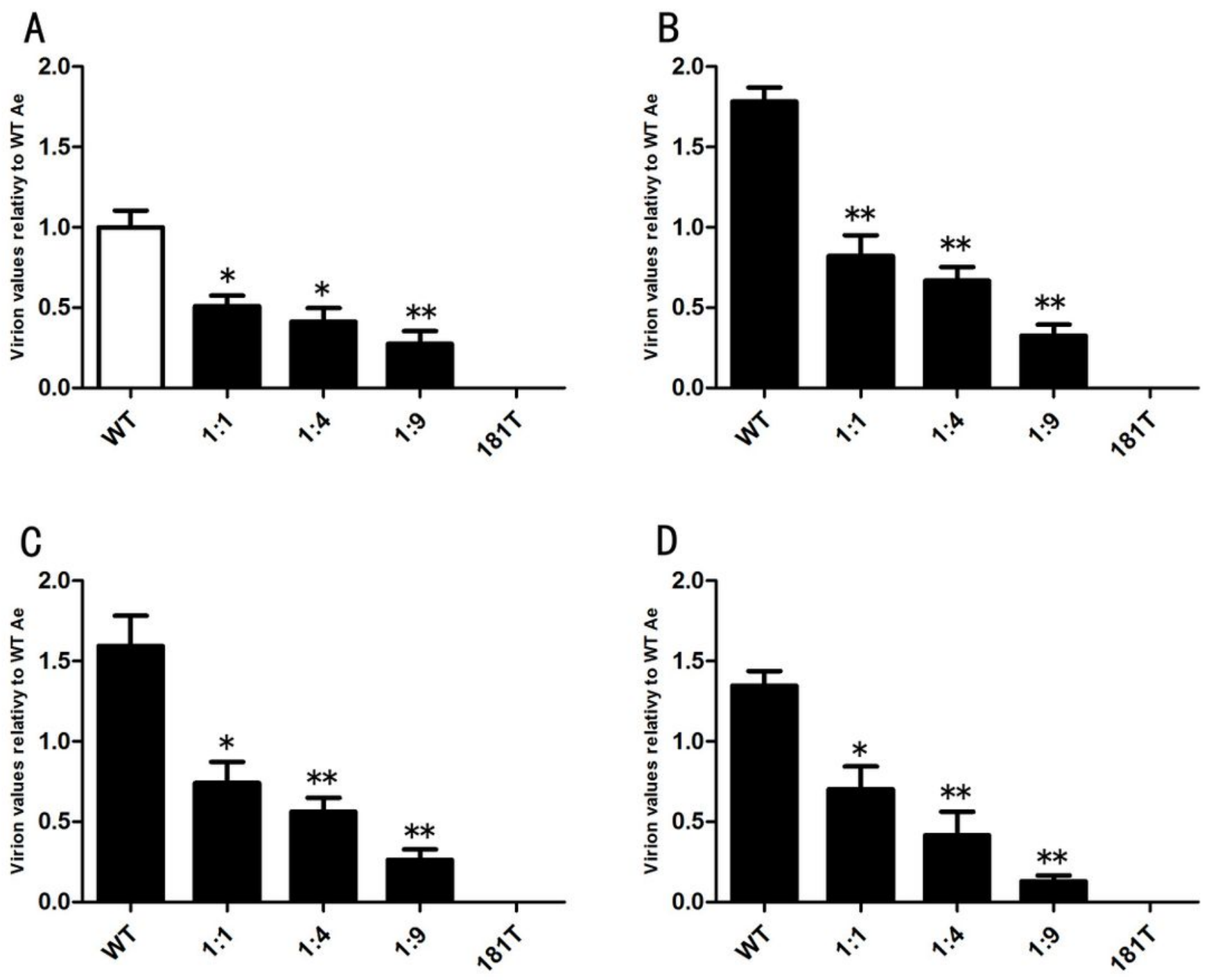

\section{Figure 3}

Extracellular expression of virion with the presence of wild type HBV in different genotypes. (A) Expression of genotype A. (B) Expression of genotype B. (C) Expression of genotype C. (D) Expression of genotype D. HBV DNA were measured 3 days after transient transfection with HBV constructs indicated. Relatively yield was normalized to wild type level. Mean value (from 3 independent experiments) were compare between different ratios. Values of genotype A wild type clone was served as a reference with the reading of 1.0 in the white bar; values of the other clones were expressed relative to this in black bars (same for the Fig.4). An asterisk represent difference of $\mathrm{P}<0.05$ and double asterisks represent difference of $\mathrm{P}<0.01$ against each wild type clone. 

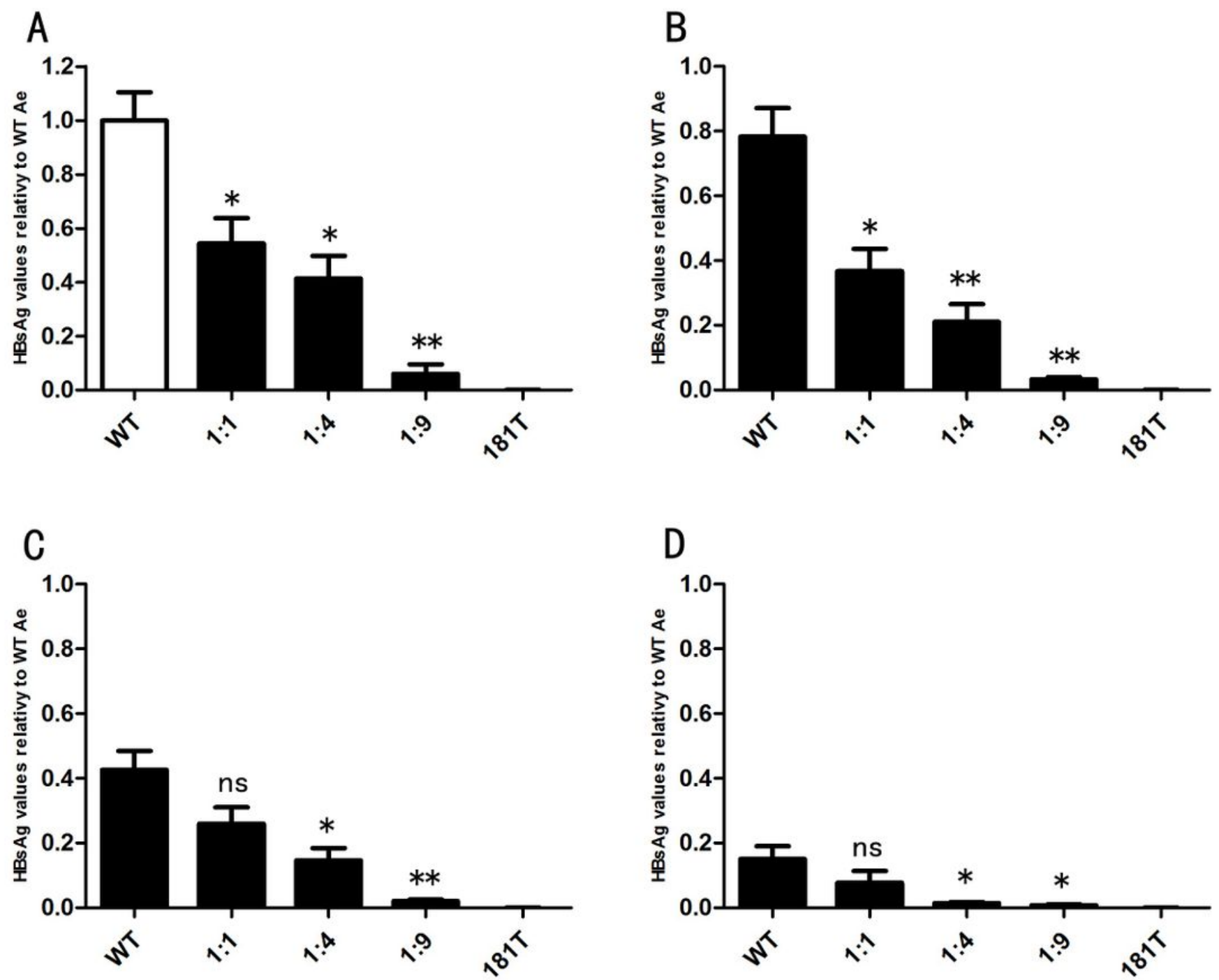

\section{Figure 4}

Extracellular expression of HBsAg with the presence of wild type HBV in different genotypes. (A) Expression of genotype A. (B) Expression of genotype B. (C) Expression of genotype C. (D) Expression of genotype D. ns represent difference of $P>0.05$, an asterisk represent difference of $P<0.05$ and double asterisks represent difference of $\mathrm{P}<0.01$ against each wild type clone. 